\title{
RANCANG BANGUN SMART kWh METER 3 FASE DENGAN KOMUNIKASI SMS GATEWAY
}

\author{
Design Of 3 Phase Smart kWh Meter Using SMS Gateway Communication
}

\author{
Rahman Hidayat ${ }^{1}$, I Made Ari Nrartha ${ }^{1}$, Ida Bagus Fery Citarsa ${ }^{1}$ \\ ${ }^{1}$ Jurusan Teknik Elektro Universitas Mataram \\ JI. Majapahit 62, Mataram, Lombok NTB, INDONESIA \\ Email: rahmanhidayatt9@gmail.com, nrartha@unram.ac.id, ferycitarsa@unram.ac.id
}

\begin{abstract}
ABSTRAK
Smart kWh meter 3 fase yang dirancang merupakan sebuah alat ukur energi listrik 3 fase yang dapat berkomunikasi dengan penggunanya sehingga memudahkan dalam pengoperasiannya. Alat ini nantinya dapat diletakkan di gardu distribusi PLN untuk mengetahui berapa energi yang disalurkan. Hasil pengujian Smart kWh meter 3 fase yang dirancang menunjukkan bahwa selisih pengukuran antara sistem monitoring yang dibuat dengan alat ukur Watt Meter DW-6163 memiliki persentase kesalahan (error) rata-rata yang rendah untuk Vrms, Irms, Daya, dan Factor daya berturut-turut pada fase R, S, dan T. Berdasarkan nilai error dihasilkan, alat yang diancang termasuk golongan kelas 1.0 menurut standar IEC No. 13B-23 dan dapat digunakan pada panel 50 $\mathrm{kVA}$. Selain itu waktu rata-rata yang dibutuhkan oleh smart kWh meter untuk mengirimkan data ke pengguna cukup singkat dari 10 kali pengiriman data yang dilakukan
\end{abstract}

Kata kunci: kWh meter, 3 fase, smart, energi, sms gateway

\begin{abstract}
The 3 phase Smart kWh meter which is designed is a 3 phase electrical energy measuring device that can communicate with its users making it easier to operate. This electrical energy measuring device can later be placed in the PLN distribution substation to find out how much energy is distributed. This device test results show that the measurement difference between the device with the Watt Meter DW-6163 measuring instrument has a low average percentage of errors for Vrms, Irms, Power and Power Factors respectively in phases $R, S$, and T. Based on the value of the error generated, this device belongs to class 1.0 according to IEC No. standard. $13 B-23$ and can be used on 50 kVA panels. In addition, the average time needed by this device to send data to the user from 10 times the data transmission is done is quite short.
\end{abstract}

Key words: $k$ Wh meter, 3 phases, smart, energy, sms gateway

\section{PENDAHULUAN}

Perkembangan teknologi saat ini mampu mengubah sesuatu pekerjaan yang dilakukan secara manual menjadi otomatis sehingga mendorong manusia untuk lebih meningkatkan lagi kemampuan di bidang teknologi. Riswandi, 2016 menggunakan mikrokontroler arduino uno, sensor arus SCT-013 yang bisa mengukur arus maksimal $30 \mathrm{~A}$, dan menggunakan modem GSM SIEMENS MC39i sebagai pengirim SMS dan sebagai SMS gateway pada web server untuk menampilkan nilai arus tanpa nilai tegangan dan daya [1]. Suryawan, 2012 menggunakan sensor arus CT 100/5 A, sensor tegangan transformator step-down dan sensor tempratur DS18B20 untuk menghasilkan alat yang mampu memonitor arus, tegangan dan suhu pada sistem daya 3 fase yang di tampilkan pada LCD [2]. Hidayat, 2018 menggunakan sensor tegangan ZMPT101B, sensor arus SCT 0130100A, modul GSM Sim800L untuk memonitor arus, tegangan, daya serta ketidakseimbangan beban yang akan dikirimkan melalui SMS setiap 3 menit [3]. Muljono, 2018 merancang smart energy meter berbasis uno dan raspberry P" untuk memonitor pemakaian energi oleh konsumen [4].

Salah satu yang mengalami perkembangan adalah sistem $\mathrm{kWh}$ meter, dimana KWh meter 3 fase yang banyak digunakan oleh PLN di gardu distribusi sekarang ini adalah $\mathrm{kWh}$ meter digital. Fungsinya hanya untuk mengukur dan menampilkan saja, belum bisa melakukan komunikasi dengan penggunanya. Penelitian 
ini akan merancang dan membuat smart kWh meter 3 fase yang dapat diakses dari jarak jauh menggunakan SMS. Smart kWh meter 3 fase merupakan sebuah alat ukur energi listrik 3 fase yang dapat berkomunikasi dengan penggunanya sehingga memudahkan pengoperasiannya. Alat ini nantinya dapat digunakan oleh PLN untuk mengetahui berapa energi yang disalurkan kepada konsumen, sehingga kWh meter 3 fase tersebut diletakkan di gardu distribusi. Peralatan $\mathrm{kWh}$ meter yang digunakan oleh PLN merupakan kWh meter 3 fase digital yang dapat mengukur besaran tegangan, arus, faktor daya, dan daya, namun semua varibel yang diukur tersebut hanya bisa di lihat pada Icd (liquid crystal display) yang ada di kWh meter tersebut, sehingga saat PLN melakukan pemeliharan rutin pada gardu distribusi, maka petugas harus datang langsung ke lokasi dimana gardu distribusi tersebut berada, hal ini sangat memakan waktu, mengingat jarak antar gardu yang satu dengan yang lain cukup jauh, sehingga sangat dibutuhkan peralatan yang bisa mengakses variabel-variabel yang terukur oleh kWh meter dari jarak jauh agar pemeliharaan gardu distribusi menjadi lebih efektif dan efisien.

\section{DASAR TEORI}

\section{Jenis-Jenis kWh Meter}

1) Berdasarkan Penggunaannya

Berdasarkan pengunaannya, kWh meter terbagi menjadi 2 yaitu $\mathrm{kWh}$ meter 1 fase dan $\mathrm{kWh}$ meter 3 fase. $\mathrm{kWh}$ meter 1 fase biasa digunakan pada perumahan masyarakat sedangkan $\mathrm{kWh}$ meter 3 fase biasa digunakan pada area industri.

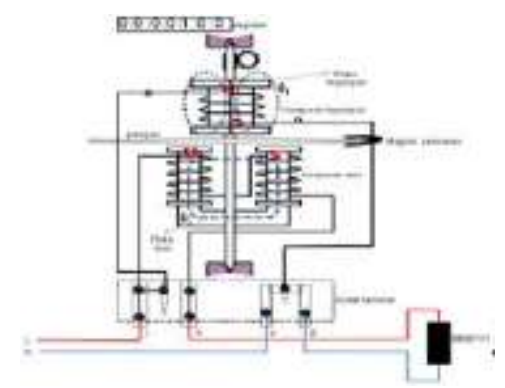

Gambar 1. KWh meter 1 fasa [5]

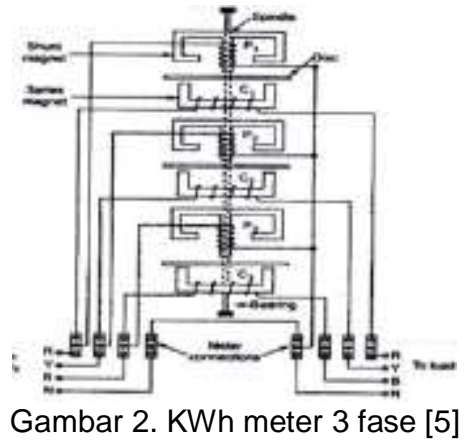

2) Berdasarkan Cara Kerjanya

Berdasarkan cara kerjanya, kWh meter dibagi menjadi 2 yaitu kWh Meter analog dan $\mathrm{kWh}$ meter digital.

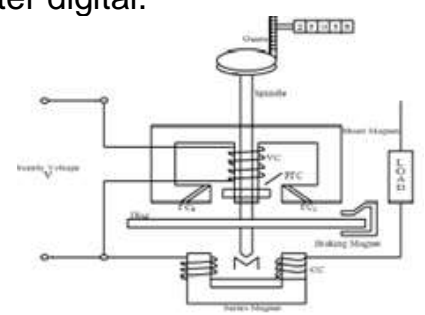

Gambar 3. KWh meter analog [5]

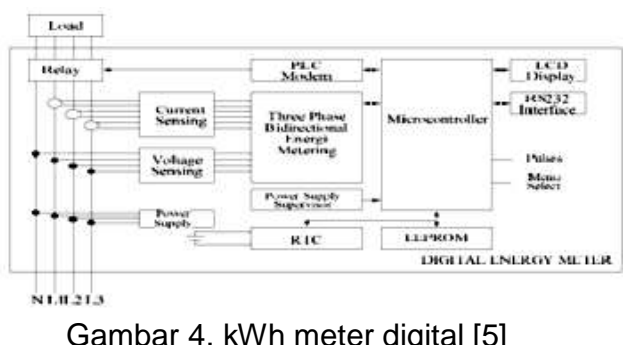

KWh meter analog bekerja dengan cara menggunakan prinsip induksi medan magnet dimana medan magnet tersebut menggerakkan piringan yang terbuat dari alumunium. Piringan tersebut akan menggerakkan counter digit sebagai tampilan jumlah penggunaan listrik konsumen. kWh meter digital bekerja dengan cara menggunakan prinsip elektronik (pulsa) untuk memantau penggunaan listrik baik secara langsung ataupun yang sudah tersimpan pada memori meter.

\section{Pengukuran Tegangan AC}

Untuk melakukan pengukuran tegangan tinggi $\mathrm{AC}$, metode yang digunakan adalah dengan cara menurunkan tegangan tinggi ke tegangan rendah.Transformator merupakan suatu peralatan listrik elektromagnetik statis yang berfungsi untuk memindahkan dan mengubah daya listrik dari suatu rangkaian listrik ke rangkaian listrik lainnya, dengan frekuensi yang sama dan perbandingan transformasi tertentu melalui suatu gandengan magnet dan bekerja 
berdasarkan prinsip induksi elektromagnetik, yaitu perbandingan tegangan antara sisi primer dan sisi sekunder berbanding lurus dengan perbandingan jumlah lilitan dan berbanding terbalik dengan perbandingan arusnya.

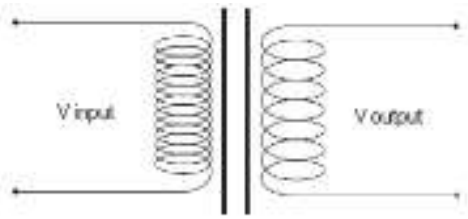

Gambar 5. Skema transformator [6]

\section{Pengukuran Arus AC}

Pengukuran arus biasanya membutuhkan resistor shunt yaitu resistor yang dihubungkan secara seri pada beban dan mengubah arus menjadi tegangan. Tegangan tersebut biasanya diumpankan ke current transformer terlebih dahulu sebelum masuk kerangkaian pengkondisi sinyal. PZEM-004T merupakan modul yang menggunakan sensor arus non invasive yang menerapkan teknologi hall effect.

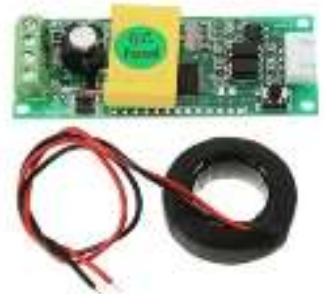

Gambar 6. Modul sensor PZEM-004T [7]

Prinsip kerja CT pada modul PZEM004T adalah sebatang penghantar dialiri arus yang dilewatkan melalui cincin toroid maka akan menimbulkan medan magnet, sehingga memiliki fluks magnet yang melingkar kemudian ditangkap oleh lilitan. CT tersebut terdiri dari kumparan sekunder dan kumparan primer yang dililitkan pada suatu inti magnet. Arus yang akan dideteksi dialirkan kekumparan primer. Arus ini menghasilkan medan maget yang mengalir kekumparan sekunder. Inti magnetik pada sensor berfungsi membuat agar fluks magnet yang dihasilkan oleh kumparan primer menembus kumparan sekunder. Perubahan fluks yang dihasilkan oleh arus primer mengakibatkan timbulnya tegangan listrik induksi pada kumparan sekunder. CT memiliki tahanan beban internal, yang berfungsi untuk menghasilkan keluaran dari sensor berupa tegangan.

\section{Daya}

Daya listrik adalah besaran listrik yang menyatakan besarnya energi yang digunakan untuk mengaktifkan komponen atau peralatan listrik / elektronik.

3) Daya nyata

Daya nyata merupakan daya listrik yang digunakan untuk keperluan menggerakkan mesin-mesin listrik atau peralatan lainnya.

$$
P=V_{\text {LN }} I_{L N} \cdot \cos \theta
$$

$P=\sqrt{ } 3 \cdot V_{L L} \cdot I_{L L} \cdot \cos \theta$.

Besar daya listrik di tentukan oleh besar atau kecilnya tegangan, arus, dan faktor daya, semakin besar tegangan dan arus maka daya listrik juga semakin besar, begitu pula dengan nilai faktor daya, dimana jika nilai faktor daya semakin mendekati 1 maka daya litrik akan semakin besar.

\section{4) Daya Semu}

Daya semu merupakan daya listrik yang melalui suatu penghantar transmisi atau distribusi. Daya ini merupakan hasil perkalian antara tegangan dan arus yang melalui penghantar.

$$
\begin{gathered}
\mathrm{S}=\mathrm{V}_{\mathrm{LN}} \times \mathrm{I}_{\mathrm{LN}} \ldots \ldots . . . \\
\mathrm{S}=\sqrt{3} \times \mathrm{V}_{\mathrm{LL}} \times \mathrm{I}_{\mathrm{LL}} . . .
\end{gathered}
$$

5) Daya Reaktif (Q)

Daya reaktif dapat dilihat pada segitiga daya merupakan selisih antara daya semu yang masuk pada penghantar dengan daya aktif pada penghantar itu sendiri, dimana daya ini terpakai untuk daya mekanik dan panas. Daya reaktif ini adalah hasil kali antara besarnya arus dan tegangan yang dipengaruhi oleh faktor daya.

$$
\begin{aligned}
& Q=V_{L N} \times I_{L N} \times \operatorname{Sin} \theta \ldots \ldots . . \\
& Q=\sqrt{ } 3 \times V_{L L} \times I_{L L} \times \operatorname{Sin} \theta . . \\
& \text { Dengan kata lain, daya }
\end{aligned}
$$

Dengan kata lain, daya listrik adalah tingkat konsumsi energi dalam suatu rangkaian listrik.

\section{Energi}

Energi listrik merupakan suatu energi utama yang sangat dibutuhkan peranannya untuk peralatan listrik atau pun energi yang disimpan di dalam arus listrik dengan satuan ampere (A) dan juga tegangan listrik yang diukur dengan satuan volt (V), sementara itu ketentuan kebutuhan konsumsi daya listrik disebut dengan satuan watt (W) untuk bisa menggerakkan motor, lampu penerangan rumah dan jalan, memanaskan dan juga mendinginkan atau pun menggerakkan kembali sebuah peralatan mekanik untuk bisa menghasilkan energi yang lain.

$E=P \times t / 3600$ 


\section{SMS Gateway}

SMS gateway adalah sebuah perangkat yang menawarkan layanan transit SMS, mentransformasikan pesan ke jaringan selular dari media lain, atau sebaliknya, sehingga memungkinkan pengiriman atau penerimaan pesan SMS dengan atau tanpa menggunakan ponsel. SMS Gateway dapat terhubung ke media lain seperti perangkat SMSC dan server milik Content Provider melalui link IP untuk memproses suatu layanan SMS. Sebuah sistem SMS Gateway, umumnya terdiri komponen Hardware (Server/Komputer yang dilengkapi dengan perangkat jaringan) dan Software (Aplikasi yang digunakan untuk pengolahan pesan). Dan untuk sebuah sistem yang besar umumnya menggunakan Database untuk penyimpanan data.

\section{Kesalahan Dalam Pengukuran (Error)}

Persen error $=$ (|nilai referensi-nilai pengukuran|)/(nilai referensi) x $100 \%$

Menurut Waluyanti dalam melakukan pengukuran hal yang cukup sulit adalah mengetahui apakah nilai hasil pengukuran merupakan nilai yang benar, karena setiap pengukuran yang menggunakan alat ukur hanya dapat menghasilkan nilai perkiraan. Dengan demikian dalam merancang sebuah alat ukur harus ada nilai pembanding yang bisa didapat dari hasil perhitungan atau dari hasil pengukuran menggunakan alat ukur yang telah diakui kemampuannya. Nilai pembanding tersebut digunakan untuk mengetahui besar kesalahan dalam pengukuran (Error), sehingga dapat diketahui tingkat ketelitian alat ukur yang dibuat yang selanjutnya akan menentukan kualitas dari alat ukur tersebut [8].

Klasifikasi alat ukur listrik menurut Standar IEC No. 13B-23 menspesifikasikan bahwa ketelitian alat ukur dibagi menjadi 8 kelas yaitu: 0,$05 ; 0,1 ; 0,2 ; 0,5 ; 1,0 ; 1,5 ; 2,5$; dan 5. Kelas-kelas tersebut artinya bahwa besarnya kesalahan alat ukur masing-masing adalah $\pm 0,05 \%, \pm 0,1 \%, \pm 0,2 \%, \pm 0,5, \pm 1,0 \%$, $\pm 1,5 \%, \pm 2,5 \%$, dan $\pm 5 \%$. Dari 8 kelas alat ukur tersebut digolongkan menjadi 4 golongan sesuai dengan daerah pemakaiannya, yaitu:

1. Golongan dari kelas $0,05,0,1$ dan 0,2 termasuk alat ukur presisi yang tertinggi, biasa digunakan pada laboratorium yang standar.
2. Golongan dari kelas 0,5 memiliki ketelitian dan tingkat presisi berikutnya dari 0,2. Alat ukur ini biasa digunakan pada pengukuran-pengukuran presisi. Alat ukur ini biasanya portabel.

3. Golongan dari kelas 1,0 memiliki ketelitian dan tingkat presisi yang lebih rendah dari alat ukur kelas 0,5 . Alat ini biasa digunakan pada alat-alat ukur portabel yang kecil atau alat ukur yang digunakan pada panel.

4. Golongan dari kelas 1,5, 2,5 dan 5. Alat ukur ini biasa digunakan pada panel panel yang tidak begitu memperhatikan presisi dan ketelitian.\#

\section{HASIL DAN PEMBAHASAN}

\section{A. Hasil Perancangan}

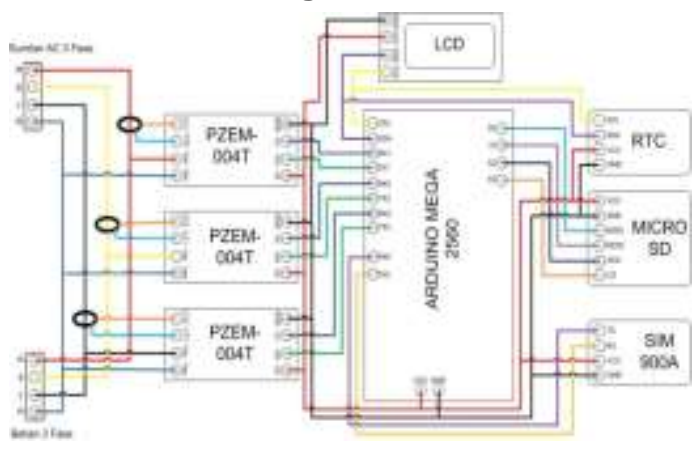

Gambar 7. Skema perancangan smart kWh meter 3 fase secara keseluruhan.

Perancangan smart $\mathrm{kWh}$ meter menggunakan beberapa komponen yaitu modul PZEM-004T yang digunakan untuk mengukur besaran-besaran listrik, kemudian Lcd dengan ukuran 20x4 yang berfungsi untuk menampilkan besaran-besaran listrik yang terukur oleh modul PZEM-004T, selanjutnya adalah SIM900A yang berfungsi untuk melakukan komunikasi SMS dengan pengguna, kemudian RTC dan modul micro SD yang digunakan sebagai data logger untuk menyimpan data besaran-besaran listrik ke dalam kartu memori. Semua komponen-komponen tersebut dihubungkan ke Arduino mega2560 sebagai mikrokontroler yang berfungsi untuk mengontrol dan memberi perintah kepada sensor-sensor yang digunakan.Pengukuran besaranbesaran listrik pada smart $\mathrm{kWh}$ meter menggunakan modul PZEM-004T.

Pada modul PZEM-004T terdapat empat pin masukan diantaranya dua pin untuk mengukur tegangan dan dua pin untuk mengukur arus, dimana pengukuran tegangan dilakukan secara paralel terhadap sumber dan beban sedangkan untuk 
pengukuran arus digunakan metode induksi elektromagnetik. Sumber untuk PZEM-004T terhubung ke pin vcc dan ground pada arduino mega2560 menggunakan kabel warna merah dan hitam sedangkan pin $R X$ TX PZEM-004T terhubung ke pin RX TX pada arduino mega2560 menggunakan kabel warna biru dan hijau.

Lcd dengan ukuran 20x4 digunakan untuk menampilkan hasil dari pengukuran PZEM-004T. Lcd yang digunakan pada penelitian ini adalah Icd yang sudah menggunakan i2c dimana terdapat empat pin yaitu pin vcc dan ground yang terhubung ke vcc dan ground arduino mega2560 menggunakan kabel merah dan hitam, kemudian pin SDA dan SCL yang terhubung ke pin SDA dan SCL pada Arduino mega2560 menggunakan kabel warna ungu dan kuning.

Data logger dibuat dengan menggunakan modul micro SD card dan modul RTC (Real Time Clock), modul micro SD card menggunakan pin SPI dan RTC menggunakan pin i2c. pin vcc dan ground pada modul micro SD card dan RTC terhubung ke vcc dan ground pada arduino mega2560 dengan kabel warna merah dan hitam, pin MISO, MOSI, SCK, dan CS pada modul micro SD card terhubung ke pin 50, 51, 52, dan 53 dari arduino mega2560 menggunakan kabel warna merah muda, biru muda, oranye, dan hijau muda.

Data logger bertujuan untuk memastikan data tetap tersimpan pada pada smart kWh meter guna untuk melakukan monitoring data secara terus-menerus setiap 1 menit. Modul SD card digunakan untuk menyimpan data pada micro SD yang dalam hal ini data disimpan dalam bentuk data TXT. Modul RTC digunakan agar setiap data tercatat waktu monitoringnya dan juga modul RTC mampu mengupdate waktu terkini apabila alat dalam kondisi mati dan dihidupkan kembali.

Perancangan SMS gateway menggunakan modul SIM900A. Pin SIM900A yang digunakan pada perancangan ini adalah empat pin yaitu pin vcc dan ground yang terhubung ke vcc dan ground pada arduino mega2560 dengan kabel warna merah dan hitam, kemudian pin RX dan TX yang terhubung ke pin 10 dan 11 pada arduino mega2560 menggunakan kabel warna ungu dan oranye.

SIM900A adalah komponen yang sangat diperlukan untuk komunikasi antara handphone penerima dan sistem alat, hal ini dikarenakan fungsi modul SIM900A ini berfungsi sebagai pengganti dari handphone yang berperan sebagai pengirim SMS melalui suatu sistem. Sistem ini juga telah dilengkapi oleh simcard seperti layaknya handphone yang biasa kita pakai. Modul komunikasi SIM900A ini menggunakan modem M10 dari Quectel yang digunakan untuk pengiriman data yang menggunakan sistem SMS (Short Message Service).

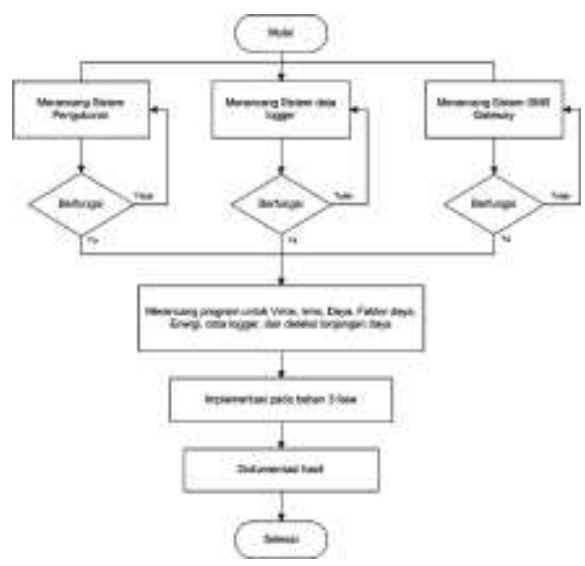

Gambar 8. Diagram alir penelitian

\section{Pengujian Smart Meter untuk Pengukuran besaran-besaran listrik}

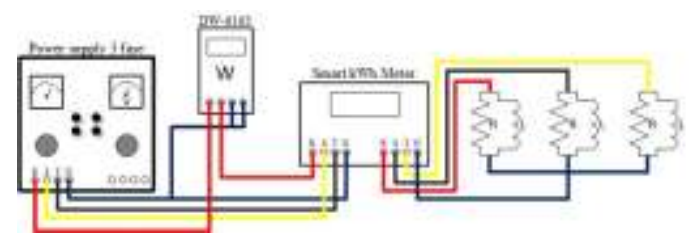

Gambar 9. Rangkaian pengujian dengan kombinasi beban resitif dan induktif

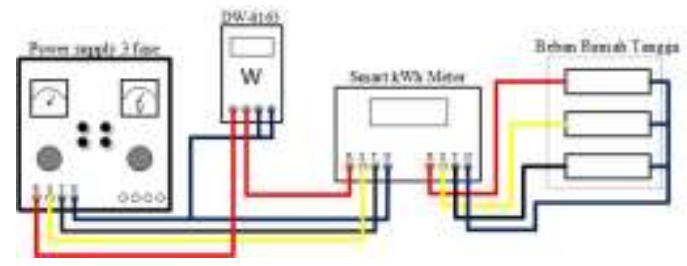

Gambar 10. Rangkaian pengujian dengan kombinasi beban listrik

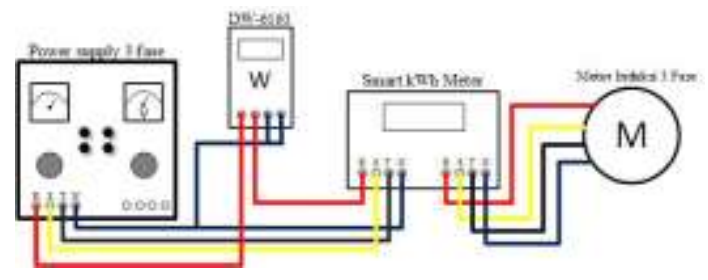

Gambar 11. Rangkaian pengujian dengan beban motor induksi 3 fase

Gambar 9, 10, 11 adalah rangkaian pengujian smart kWh meter 3 fase. Sumber 3 fase dihubungkan ke Smart kWh meter 
sebagai supply utama ke beban, beban pada tiap fase tersebut digabungkan dengan cara hubung bintang $(\mathrm{Y})$. Alat ukur Watt Meter DW-6163 digunakan sebagai acuan dalam pengujian untuk menentukan apakah besaran-besaran listrik yang terukur di smart $\mathrm{kWh}$ meter sesuai dengan yang terukur pada Watt Meter DW-6163.

Tabel 1. Hasil Pengujian Smart Kwh Meter Untuk Pengukuran Besaran-Besaran Listrik

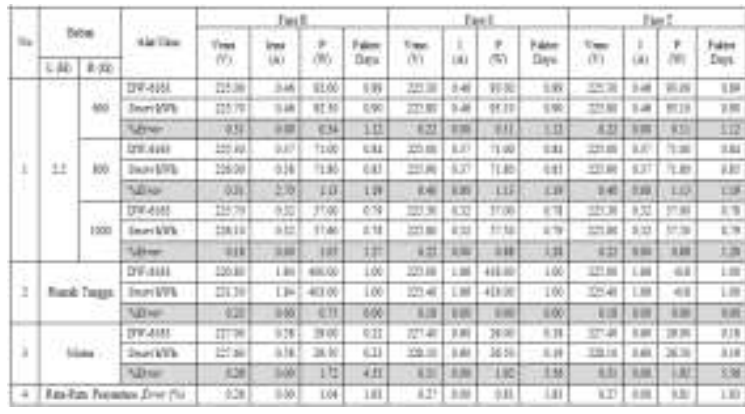

Pengambilan data pengujian smart kWh meter yang dibuat dengan kombinasi beban $\mathrm{RL}$, beban rumah tangga, dan motor induksi 3 fase ditunjukkan pada Gambar 12, dimana beban rumah tangga yang digunakan adalah kombinasi dari lampu, pemanas air, setrika, penanak nasi, ponsel, laptop dan lcd.

Pengujian ini bertujuan untuk mengetahui kinerja dari sistem monitoring yang dibuat dapat bekerja dengan baik atau tidak. Data yang didapatkan dari hasil pengujian pada saat menggunakan kombinasi beban $\mathrm{RL}$ terlihat bahwa dengan nilai Vrms yang relatif konstan dan $L$ tetap, maka saat nilai $\mathrm{R}$ di ubah menjadi semakin besar, didapatkan nilai arus yang semakin kecil, begitu pula dengan daya dan faktor daya yang didapatkan akan semakin kecil seiring dengan bertambahnya nilai beban $R$ yang diberikan.

Hasil pengujian didapat selisih pengukuran antara sistem monitoring yang dibuat dengan alat ukur Watt Meter DW6163. Untuk mendapatkan nilai persentase kesalahan (error) digunakan persamaan 2.11 sehingga diperoleh error rata-rata untuk Vrms, Irms, Daya, dan Factor daya berturutturut pada fase $\mathrm{R}$ adalah $0.26 \%, 0 \%, 1.04 \%$, $1.63 \%$, untuk fase $S$ adalah $0.27 \%, 0 \%$, $0.81 \%$, $1.83 \%$, dan untuk fase $\mathrm{T}$ adalah $0.21 \%, 0 \%, 0.99 \%, 0.72 \%$.

\section{Pengujian Pencatatan Energi pada Smart kWh Meter}

Tabel 2. Hasil Pengujian Konsumsi Energi

\begin{tabular}{|c|c|c|c|c|c|c|c|c|c|c|c|c|c|c|}
\hline \multirow{2}{*}{$\mathrm{Se}$} & \multicolumn{2}{|c|}{ Betan } & \multicolumn{3}{|c|}{$D_{y, y}(n)$} & \multicolumn{3}{|c|}{ Eragi (mi) } & \multicolumn{3}{|c|}{ 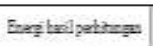 } & \multicolumn{3}{|c|}{ Prscense anx (A) } \\
\hline & $\mathrm{I}$ (H) & $\mathrm{R}(\mathrm{I})$ & I. & 3 & I & R. & \& & I & 3 & 5 & $T$ & i. & 5 & $T$ \\
\hline \multirow{3}{*}{1} & \multirow{3}{*}{22} & 692 & 929 & 91.1 & 328 & 3.10 & 3 & 305 & 3.11 & 321 & 319 & 211 & 333 & min \\
\hline & & $8 m$ & 718 & 72.5 & 717 & 239 & 219 & 235 & 219 & 213 & 237 & 214 & 214 & 1 \\
\hline & & IKN & 57.6 & 575 & 524 & 298 & 194 & 185 & 191 & 192 & 191 & 1 & 235 & 435 \\
\hline 2 & \multicolumn{2}{|c|}{ Prod Targs } & 423 & 418 & 423 & 13.42 & 133 & 143 & 13.45 & 1299 & 14.68 & 210 & 224 & 205 \\
\hline 3 & \multicolumn{2}{|c|}{ Satox } & 295 & 266 & 21.5 & LII & 0,98 & 0.83 & 195 & 693 & $2 \mathrm{E} 2$ & 271 & 275 & 122 \\
\hline 4 & \multicolumn{11}{|c|}{ 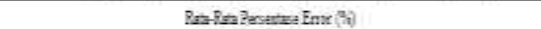 } & 252 & 295 & 2.54 \\
\hline
\end{tabular}

\section{Pengujian Smart kWh Meter Untuk Komunikasi SMS Gateway}

Tabel 3. Kode Akses Pada Smart Meter

\begin{tabular}{|c|c|c|}
\hline No. & Keterangan & $\begin{array}{c}\text { Kode } \\
\text { Akses }\end{array}$ \\
\hline 1 & $\begin{array}{c}\text { Angka referensi untuk mengganti kata } \\
\text { sandi }\end{array}$ & 325 \\
\hline 2 & Kata sandi default & 1234 \\
\hline 3 & $\begin{array}{c}\text { Angka referensi untuk mengganti } \\
\text { nomor pengguna }\end{array}$ & 326 \\
\hline 4 & $\begin{array}{c}\text { Perintah untuk mengakses nilai } \\
\text { tegangan dan arus }\end{array}$ & $\mathrm{VI}$ \\
\hline 6 & $\begin{array}{c}\text { Perintah untuk mengakses nilai daya, } \\
\text { energi dan faktor daya masing-masing } \\
\text { fase }\end{array}$ & $\mathrm{PEF}$ \\
\hline 7 & $\begin{array}{c}\text { Perintah untuk mengakses daya total, } \\
\text { energi total, dan factor daya total. }\end{array}$ & $\mathrm{TOT}$ \\
\hline Kaksimum pengunale aks untuk mengatur batas \\
\hline
\end{tabular}

Kode-kode akses tersebut bertujuan agar memudahkan pengguna untuk melakukan komunikasi dengan smart kWh meter, selain itu komunikasi antara pengguna dengan smart kWh meter juga akan lebih aman karena smart kWh meter dilengkapi dengan kata sandi yang hanya diketahui oleh pengguna.

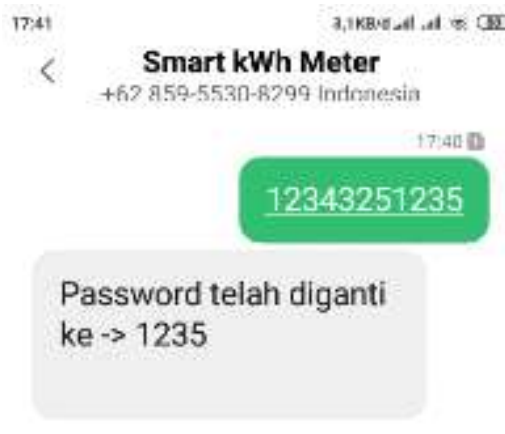

Gambar 12. Penggantian kata sandi

Smart kWh meter memiliki sistem keamanan berupa kata sandi yang terdiri dari 4 digit angka, kata sandi default yang diatur adalah angka 1234. Jika pengguna ingin melakukan penggantian kata sandi, maka dapat dilakukan dengan cara mengirimkan 
perintah berupa SMS kepada smart kWh meter dengan mengetikkan kata sandi awal dilanjutkan dengan angka angka referensi untuk penggantian sandi kemudian dilanjutkan dengan kata sandi baru.

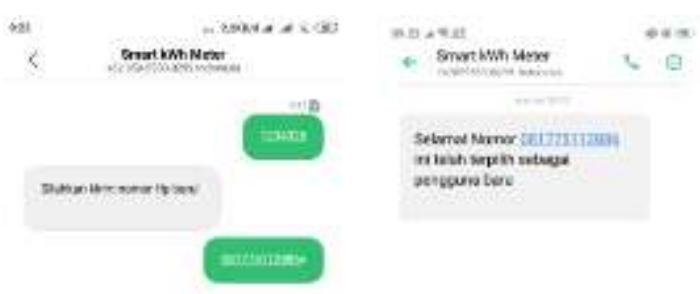

Gambar 13. Penggantian nomor pengguna

Selain menggunakan kata sandi untuk keamanan, pengguna smart kWh meter ini juga dapat mengganti nomor ponsel. Untuk melakukan penggantian nomor, dapat dilakukan dengan cara mengirimkan perintah berupa SMS kepada smart kWh meter dengan mengetikkan kata sandi dilanjutkan dengan nomor referensi untuk penggantian nomor yaitu 326, setelah SMS tersebut dikirmkan ke smart meter, sesaat kemudian pengguna akan menerima SMS berupa perintah untuk mengirimkan nomor baru yang akan digunakan, jika nomor baru telah dikirmkan maka smart kWh meter akan mengirimkan pemberitahuan ke nomor yang baru bahwa nomor tersebut berhasil digunakan sebagai pengguna baru.
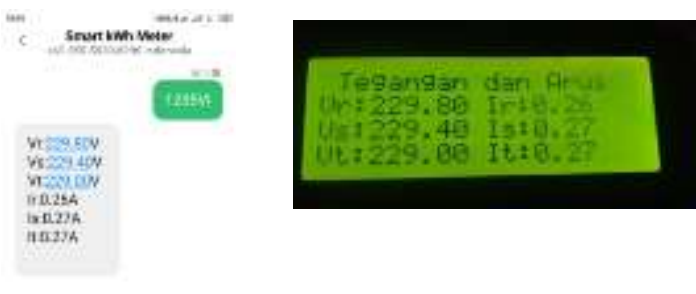

Gambar 14. Hasil monitoring tegangan dan arus dengan SMS

Pengguna dapat melakukan monitoring data tegangan dan arus dengan mengirimkan perintah berupa SMS dengan menuliskan kata sandi dilanjutkan dengan VI. Dari Gambar 16 menunjukkan bahwa data tegangan dan arus yang dikirmkan melalui SMS oleh smart kWh meter kepada pengguna sesuai dengan yang di tampilkan pada lcd di smart kWh meter tersebut. Waktu yang dibutuhkan oleh smart kWh meter untuk mengirimkan data arus dan tegangan perfase adalah rata-rata 6.65 detik dari 10 kali pengiriman data yang dilakukan.
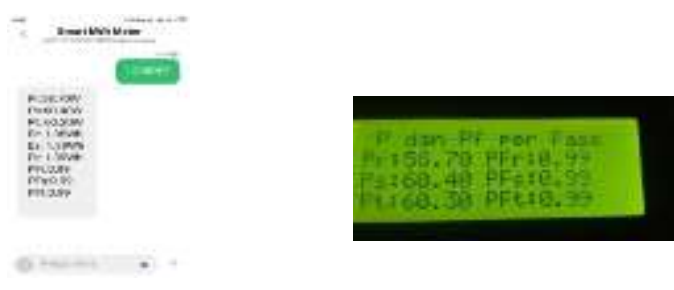

Gambar 15. Hasil monitoring daya, energi, dan faktor daya dengan SMS

Pengguna dapat melakukan monitoring data daya perfase, energi perfase, dan faktor daya perfase dengan mengirimkan perintah berupa SMS dengan menuliskan kata sandi dilanjutkan dengan PEF. Dari Gambar 17 menunjukkan bahwa data besaran-besaran listrik yang dikirmkan melalui SMS oleh smart kWh meter kepada pengguna sesuai dengan yang di tampilkan pada Icd di smart kWh meter tersebut. Waktu yang dibutuhkan oleh smart kWh meter untuk mengirimkan data daya, energi, dan faktor daya adalah rata-rata 7.32 detik dari 10 kali pengiriman data yang dilakukan.

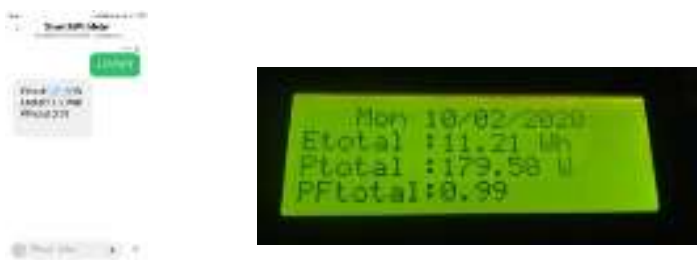

Gambar 16. Hasil monitoring besaranbesaran total dengan SMS gateway

Pengguna dapat melakukan monitoring data daya total, energi total, dan faktor daya total dengan mengirimkan perintah berupa SMS dengan menuliskan kata sandi dilanjutkan dengan TOT. Dari Gambar 18 menunjukkan bahwa data besaran-besaran listrik yang dikirmkan melalui SMS oleh smart $\mathrm{kWh}$ meter kepada pengguna sesuai dengan yang di tampilkan pada lcd di smart kWh meter tersebut. Waktu yang dibutuhkan oleh smart kWh meter untuk mengirimkan data energi total, daya total dan factor daya total adalah rata-rata 5.49 detik dari 10 kali pengiriman data yang dilakukan. 


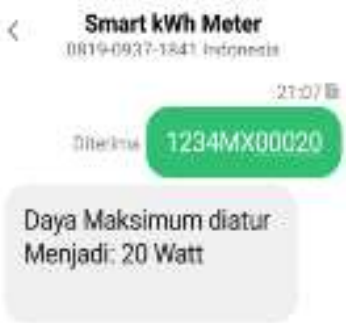

Gambar 17. Pengaturan Daya maksimum

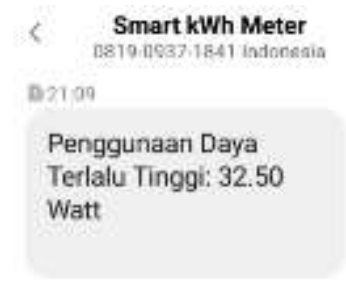

\section{Gambar 18. Tampilan SMS saat daya} melebihi daya maksimum

Pengguna dapat mengatur daya maksimum yang dapat melewati smart kWh meter, apabila daya beban yang diberikan melebihi dari daya yang telah diatur pada smart kWh meter maka alat tersebut akan mengirimkan SMS pemberitahuan kepada pengguna bahwa daya yang di berikan melebihi dari batas maksimal, apabila daya tersebut tidak dikurangi sesuai dengan batas maksimum yang telah diatur maka smart $\mathrm{kWh}$ meter akan terus mengirimkan pemberitahuan setiap 1 menit.

Untuk mengatur daya maksimum tersebut pengguna dapat mengirimkan perintah berupa SMS dengan menuliskan kata sandi dilanjutkan dengan MX kemudian menuliskan berapa daya maksimum yang diinginkan.

\section{Pengujian logger data pada smart meter}

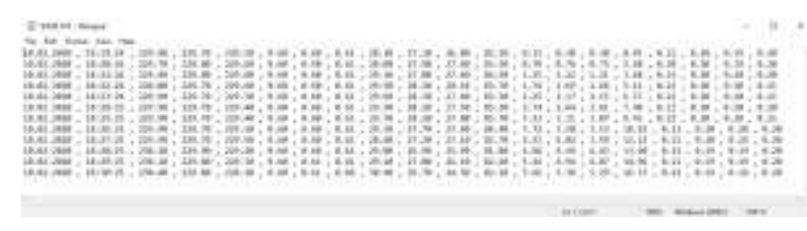

Gambar 19. Tampilan data logger

Pengujian logger data bertujuan untuk memastikan data tetap tersimpan pada pada smart kWh meter guna untuk melakukan monitoring data secara terus-menerus setiap 1 menit. Tampilan hasil pencatatan data pada modul micro SD yang ditunjukkan pada
Gambar 4.11 memiliki urutan data dari kiri ke kanan adalah tanggal, bulan, tahun, jam, menit, detik, tegangan fase $R$, tegangan fase $S$, tegangan fase $T$, arus fase $R$, arus fase $S$, arus fase $T$, daya fase $R$, daya fase $S$, daya fase $T$, daya total, energi fase $R$, energi fase.S, energi fase $T$, energi total, faktor daya fase $R$, faktor daya fase $S$, faktor daya fase $T$, faktor daya total. Dalam satu kali pencatatan data pada modul micro SD menghabiskan memori sebesar 157 byte, sehingga untuk pencatatan data selama 1 tahun smart kWh meter hanya menghabiskan memori sebesar $78 \mathrm{MB}$.

\section{PENUTUP}

\section{Kesimpulan}

Selisih pengukuran antara sistem monitoring yang dibuat dengan alat ukur Watt Meter DW-6163 diperoleh persentase kesalahan (error) rata-rata yang cukup rendah untuk Vrms, Irms, Daya, dan Factor daya berturutturut pada fase $\mathrm{R}$ adalah $0.26 \%, 0 \%, 1.04 \%$, $1.63 \%$, untuk fase $\mathrm{S}$ adalah $0.27 \%, 0 \%$, $0.81 \%, 1.83 \%$, dan untuk fase $\mathrm{T}$ adalah $0.21 \%, 0 \%, 0.99 \%, 0.72 \%$. Sedangkan waktu rata-rata yang dibutuhkan oleh smart $\mathrm{kWh}$ meter untuk mengirimkan data ke pengguna cukup singkat yaitu 6.65 detik (tegangan dan arus per fase), 7,32 detik (daya, energy dan factor daya perfase) dan 5,49 detik (daya, energy dan factor daya total) dari 10 kali pengiriman data yang dilakukan.. Berdasarkan nilai error dihasilkan, alat yang diancang termasuk golongan kelas 1.0 menurut standar IEC No. 13B-23 dan dapat digunakan pada panel 50 kVA.

\section{Saran}

Smart kWh meter ini dapat dikembangkan untuk pengukuran pada trafo distribusi di atas 50 KVA dengan mengganti sensor arus dan sensor tegangan sesuai dengan kebutuhan arus dan tegangan.

\section{REFERENSI}

[1] Riswandi, "Pemodelan Alat Monitoring Keseimbangan Arus Listrik Tiga Phasa Menggunakan Arduino dan SMS Gateway Dengan Berbasis Web", Jurnal Informatika SIMANTIK Vol.1, No.1, Hal.12-16, 2016.

[2] D.W. Suryawan, Sudjadi, dan Karnoto, "Rancang Bangun Sistem Monitoring Tegangan, Arus Dan Temperatur Pada Sistem Pencatu Daya Listrik Di Teknik Elektro Berbasis Mikrokontroler Atmega 
128", TRANSIENT, Vol. 1, No. 4, Hal. 244250, 2012.

[3] P. Hidayat, Supriyatna, dan A.S. Rachman, "Prototype Sistem Monitoring Gardu Distribusi Jaringan Tegangan Rendah Berbasis Arduino Mega 2560", Jurnal diakses dari http://eprints.unram.ac.id/10711/, 2018.

[4] A.B Muljono, "Rancang Bangun Smart Energy Meter Berbasis UNO dan Raspberry Pi', Jurnal Rekayasa Elektrika Vol. 14, No. 1, hal. 9-18, 2018.

[5] S. Agrath, "Perancangan Smart 3 Phase Power Meter berbasis Arduino", Tugas Akhir, Departemen Teknik Elektro, Fakultas Teknik, Universitas Sumatera Utara, Medan, 2019.

[6] H. Sasmita, I.M.A. Nrartha, I.M.B, Suksmadana, I.M.B., "Rancang Bangun Energi Meter Dan Analisis Karakteristik Energi Beban Listrik Berbasis Raspberry Pi", Dielektrika, Vol. 5, No. 1, Hal. 64 - 72, 2018.

[7] R.P.W., Putra, M. Mukhsim, F. Rofii, "Sistem Pemantauan dan Pengendalian Modul Automatic Transfer Switch (ATS) Melalui Android Berbasis Arduino", TELKA, Vol.5, No.1, Hal. 43-54, 2019.

[8] S. Waluyanti, "Alat Ukur dan Teknik Pengukuran Jilid 1", Jakarta: Direktorat Pembinaan Sekolah Menengah Kejuruan, Direktorat Jenderal Manajemen Pendidikan Dasar dan Menengah, Departemen Pendidikan Nasional, 2008. 